\title{
Porous Ceramic Characteristics Sintered from Waste Diatomite and Sodium Silicate Sand
}

\author{
Kae-Long Lin and Ju-Ying Lan
}

\begin{abstract}
This study examines potential waste diatomite and sodium silicate sand reuse to prepare water absorption and retain porous ceramics. The operating conditions are constant pressure $(5 \mathrm{MPa})$, sintering temperature $\left(1000-1270^{\circ} \mathrm{C}\right)$, sintering time $(2 \mathrm{~h})$, waste diatomite containing sodium silicate sand at different proportions $(0-20 \%)$, respectively. The porous ceramic samples containing sodium silicate sand show low thermal conductivity properties $(0.278-0.562 \mathrm{~W} / \mathrm{mK})$, probably owing to the more pores than those in the concrete $(1.458$ $\mathrm{W} / \mathrm{mK})$. Water release $\left(t_{1 / 2}\right.$ value) by the porous ceramic samples is decelerated by porous ceramic samples containing sodium silicate sand, due to the synergy effect of high water absorption by the sodium silicate sand and better than in the foamed glass material $(4 \mathrm{~h})$. Porous ceramic samples containing sodium silicate sand is highly promising for use in water absorption and retention applications.
\end{abstract}

Index Terms-Porous ceramics, thermal conductivity, compressive strength, sodium silicate sand.

\section{INTRODUCTION}

Rising temperatures in large cities poses an increasing environmental threat, especially during the summer in Taiwan. This predicament arises from the increasing amount of heat generated by human activity (e.g., vehicles and air conditioners) and the increasing amount of surface areas covered by artificial materials with a high solar absorption capacity. This global warming phenomenon is referred to as the "heat island effect" [1].

Porous ceramics with well-defined macroscopic shapes and $\mathrm{h}$ igh mechanical stability can be fabricated using novel processing route, while retaining the intrinsic porosity of the porous powder from which they are manufactured [2], [3]. Sintering is a thermal process that transforms a compact powder into a bulk material, and is used in mass-producing complex-shaped components. Sintering is a complex process of microstructural evolution, which involves bond formation, neck growth, pore channel closure, pore shrinkage, densification, coarsening, and grain growth. The force that acts between particles, the sintering force, comprises both surface tension and grain boundary tension. Sintering is one of the most important technological processes in the powder metallurgy and ceramic industries. A rational theory of sintering should predict the routes of production of the required structure of a sintered body in order to provide its physico-chemical and physico-mechanical properties which are determined by this structure [4].

Manuscript received January 4, 2013; revised March 4, 2013.

Kae-Long Lin and Ju-Ying Lan are with the Department of Environmental Engineering, National Ilan University, I-Lan, Taiwan (e-mail kllin@niu.edu.tw,doris_tension@hotmail.com).
Water absorption and retention of porous ceramics as building materials are characterized by their permanence, heat insulation [5] and water retention. This study demonstrates the feasibility of producing water absorption and retention of porous ceramic monoliths from diatomite and sodium silicate sand. The ability to use diatomite and sodium silicate sand produced as water absorption and retention of porous ceramic is also examined by studying their water retention and thermal conductivity properties. Their mineral composition and crystalline phase of porous ceramic monoliths are determined using Fourier transform infrared spectroscopy (FTIR). Finally, the micro-structure of porous ceramic monoliths is determined using scanning electron microscopy (SEM).

\section{Material AND MethodS}

\section{A. Materials}

The waste diatomite and sodium silicate sand used were collected from the food-processing industry and mold manufacturer located in Taipei County, Taiwan. In total, 500 $\mathrm{kg}$ of waste diatomite and sodium silicate sand were obtained from the food-processing industry and mold manufacturer, respectively. The waste diatomite and sodium silicate sand were pulverized using a ball mill until they could pass through a 100 mesh $(0.149 \mathrm{~mm})$ sieve. The resultant pulverized waste diatomite and sodium silicate sand were then stored in a desiccator until testing.

\section{B. Preparation of Compacted Sintered Porous Ceramics Samples}

The waste diatomite and the sodium silicate sand samples were oven-dried at $105^{\circ} \mathrm{C}$ for $24 \mathrm{~h}$ and ground in a ball mill to form fine powders (until pass through a 100 mesh sieve) suitable for pressing. The powder samples were mixed with each other to prepare a known mass percentage of sodium silicate sand in diatomite in different concentration of sodium silicate sand $(0-20 \%$ by mass) to produce porous ceramics samples. The content of the sodium silicate sand in the waste diatomite mixture was varied from $0 \%$ to $20 \%$ by mass. The samples were compacted at $5 \mathrm{MPa}$ to form cylinder specimens $(51.8 \mathrm{~mm}(\Phi) \times 15 \mathrm{~mm}(\mathrm{H}))$ that were then desiccated before testing. The compacted porous ceramic specimens were placed on a platinum plate and burnt in an electrically heated furnace using a ramp rate of $5^{\circ} \mathrm{C} \min ^{-1}$. The porous ceramic samples were then sintered at temperatures between $1000^{\circ} \mathrm{C}$ and $1270^{\circ} \mathrm{C}$ for 120 minutes. The sintered samples were then cooled to room temperature and stored in a desiccator for subsequent physical properties testing and microstructure analyses. 


\section{Characterization of Sintered Porous Ceramics Specimens}

The chemical composition and physical characteristics of the porous ceramic pellets and sintered products were analyzed. The porous ceramic samples were digested using $\mathrm{HNO}_{3} / \mathrm{HClO}_{4} / \mathrm{HF}$ according to NIEA R355.00C and then analyzed with Inductively Coupled Plasma Atomic Emission Spectroscopy (ICP-AES) for the major elements. Sample mechanical quality was obtained by performing crushing strength tests. In this test, an oven-dried sample was placed in a steel cylinder with an internal diameter of $51.8 \mathrm{~mm}$ and a height of $15 \mathrm{~mm}$. The samples were filled into the cylinder up to an upper incision mark. The cylinder was covered and pressed down using a steel puncheon until the upper level of the porous ceramic sample was reduced by a prescribed distance. The crushing strength value was calculated as the ratio between the load and the cross-sectional area of the cylinder in stress units..

Chemical composition: The X-ray fluorescence (XRF) analysis was performed using an automated RIX 2000 spectrometer. Unconfined compressive strength (ASTM C39-72): Three specimens were used for the compressive strength tests while the fourth one was used for the microstructure examination.

A quick thermal conductivity meter based on ASTM C 1113-90 hot-wire method was used (ASTM C 1113-90) [6].

Water absorption of the porous ceramic samples was determined by immersing them in water at $20^{\circ} \mathrm{C}$ and weighing after predetermined time intervals up to $24 \mathrm{~h}$. The water absorbed after $24 \mathrm{~h}$ was defined as the water absorption (Wa (\%)). Release of the absorbed water was evaluated in an atmosphere with the relative humidity controlled at $55 \%$ using a saturated $\mathrm{Mg}\left(\mathrm{NO}_{3}\right)_{2} \cdot 6 \mathrm{H}_{2} \mathrm{O}$ solution. The water release rate was then evaluated from the time at which half the absorbed water was lost $\left(\mathrm{t}_{1 / 2}(\mathrm{~h})\right)$ [5].

\section{RESUlTS AND DisCUSSION}

\section{A. Characteristics of Waste Diatomite and the Sodium Silicate Sand}

The densities of the waste diatomite and the Sodium Silicate Sand were 1.26 and $0.78 \mathrm{~g} \mathrm{~cm}^{-3}$, respectively. The $\mathrm{pH}$ of the waste diatomite and the sodium silicate sand were 7.21 and 10.91, respectively. Table I show chemical composition of the waste diatomite and sodium silicate sand, respectively.

TABLE I: CHEMICAL COMPOSITION OF THE WASTE DiATOMITE AND SODIUM SILICATE SAND

\begin{tabular}{ccc}
\hline Chemical Composition & Waste Diatomite & Sodium Silicate Sand \\
\hline $\mathrm{SiO}_{2}(\%)$ & 93.6 & 82.9 \\
$\mathrm{Al}_{2} \mathrm{O}_{3}(\%)$ & 1.08 & 4.42 \\
$\mathrm{Fe}_{2} \mathrm{O}_{3}(\%)$ & 0.875 & 0.81 \\
$\mathrm{CaO}(\%)$ & 0.20 & 1.69 \\
$\mathrm{MgO}(\%)$ & - & 0.13 \\
$\mathrm{SO}_{3}(\%)$ & 0.04 & - \\
$\mathrm{K}_{2} \mathrm{O}(\%)$ & 0.19 & - \\
\hline \hline
\end{tabular}

\section{B. Mechanical Characteristics of Porous Ceramics}

Table II shows the open porosity of the pure diatomite specimens that were fired at various temperatures. The porosity declined slowly from $1000{ }^{\circ} \mathrm{C}$ to $1270{ }^{\circ} \mathrm{C}$ (from $64.02 \%$ to $61.27 \%$ ). However, the rate of change was not constant. The high porosity was attributed to the unique porous mineralogical character of diatomite that contained $20 \%$ sodium silicate sand, the porosity of which did not change considerably during sintering. First, the open porosity declined gradually from $60.01 \%$ at $1000{ }^{\circ} \mathrm{C}$ to $59.41 \%$ at $1100{ }^{\circ} \mathrm{C}$. In the second stage, the porosity decreased from $58.75 \%$ at $1200{ }^{\circ} \mathrm{C}$ to $54.72 \%$ at $1270{ }^{\circ} \mathrm{C}$, and the rate of decline was higher than that in the first stage. In this stage, sintering reduced the volume, and most of the pores were closed. This indicated a simpler morphology that was attributed to a mass diffusion transfer and pure sintering shrinkage [7].

The water absorption rate, which is the weight of the moisture in the pores as a fraction of the weight of the sintered specimen, is an effective index of the quality of porous ceramics. Table II shows the results of the water absorption tests on various sodium silicate sand- diatomite mixtures that were heated at four temperatures. Water absorption increased from $76.2 \%$ to $93.4 \%, 73.1 \%$ to $91.1 \%$, $70.6 \%$ to $87.9 \%$, and $65.1 \%$ to $85.2 \%$, with heating temperatures of $1000{ }^{\circ} \mathrm{C}, 1100{ }^{\circ} \mathrm{C}, 1200{ }^{\circ} \mathrm{C}$, and $1270{ }^{\circ} \mathrm{C}$, respectively. The results show that, as the sodium silicate sand content declined, the water absorption of the porous ceramic samples increased. We observed a near-linear dependence of water absorption on the sodium silicate sand contents (from 10 to $20 \mathrm{wt} . \%$ ) in the samples of diatomite that contained sodium silicate sand. Furthermore, the amount of water absorbed by the porous ceramics decreased with an increase in the heating temperature. The decline in the rate of water absorption with increasing heating temperature $\left(1200^{\circ} \mathrm{C}\right)$ suggests that local liquid-phase sintering occurred, which contributed to a decrease in pore volume and the water absorption rate. Water absorption of the materials in this study is consistent with the trend that was first described by Furlani et al.; that is, the sintering behavior of ceramics is affected by the formation of a "transitory liquid" phase, which improves the densification of the sintered samples. The bonding capacity of the mixture is related to the amount of the sodium silicate sand added to the mixture.

The compressive strength is the crucial index of the engineering quality of porous ceramic material. Table II shows the compressive strength test results for porous ceramics made from diatomite and sodium silicate sand mixtures. The compressive strength of the porous ceramics increased when the heating temperature increased from 1000 ${ }^{\circ} \mathrm{C}$ to $1270{ }^{\circ} \mathrm{C}$. The results showed that the optimal heating temperature that maximized the compressive strength was $1270{ }^{\circ} \mathrm{C}$. The compressive strength of the mixed porous ceramic samples of diatomite that contained the sodium silicate sand decreased slightly when the heating temperature increased above $1200{ }^{\circ} \mathrm{C}$. The porous diatomite ceramic strength decreased when up to $20 \%$ of the sodium silicate sand was added to the porous ceramics that were heated to $1200{ }^{\circ} \mathrm{C}$. The sodium silicate sand can be converted into porous ceramics by using this method. Consequently, the sodium silicate sand can be blended with diatomite to 
produce porous ceramics.

TABLE II: MECHANICAL CHARACTERISTICS OF POROUS CERAMICS

\begin{tabular}{|c|c|c|c|c|c|c|}
\hline $\begin{array}{c}\text { Mechanic } \\
\text { Characteristic }\end{array}$ & $\begin{array}{c}\text { Heating } \\
\text { Temperature } \\
\left({ }^{\circ} \mathrm{C}\right)\end{array}$ & \multicolumn{5}{|c|}{$\begin{array}{l}\text { Sodium Silicate Sand Replacement Level } \\
\qquad(\%)\end{array}$} \\
\hline \multirow{5}{*}{$\begin{array}{l}\text { Porosity } \\
(\%)\end{array}$} & & 0 & 5 & 10 & 15 & 20 \\
\hline & 1000 & 64.02 & 62.75 & 61.22 & 61.04 & 60.01 \\
\hline & 1100 & 63.41 & 62.47 & 60.98 & 60.36 & 59.41 \\
\hline & 1200 & 62.59 & 62.13 & 60.78 & 59.70 & 58.75 \\
\hline & 1270 & 61.27 & 59.90 & 58.05 & 57.61 & 54.72 \\
\hline \multirow{4}{*}{$\begin{array}{c}\text { Water } \\
\text { absorption } \\
(\%)\end{array}$} & 1000 & 93.39 & 88.08 & 83.30 & 80.32 & 76.20 \\
\hline & 1100 & 91.13 & 85.65 & 80.74 & 77.01 & 73.15 \\
\hline & 1200 & 87.85 & 83.61 & 78.47 & 74.40 & 70.58 \\
\hline & 1270 & 85.23 & 79.63 & 72.83 & 70.88 & 65.03 \\
\hline \multirow{4}{*}{$\begin{array}{l}\text { Compressive } \\
\text { strength } \\
(\mathrm{MPa})\end{array}$} & 1000 & 2.48 & 3.18 & 3.36 & 3.61 & 3.68 \\
\hline & 1100 & 4.36 & 4.89 & 5.37 & 5.66 & 6.33 \\
\hline & 1200 & 5.92 & 6.35 & 6.95 & 7.40 & 8.52 \\
\hline & 1270 & 6.10 & 7.74 & 8.78 & 9.76 & 10.38 \\
\hline
\end{tabular}

\section{Thermal Conductivity of Porous Ceramic Samples}

Fig. 1 shows the variation in thermal conductivity of waste diatomite containing sodium silicate sand sintered porous ceramic samples at various temperatures. When the heating temperature was increased from $1000{ }^{\circ} \mathrm{C}$ to $1200{ }^{\circ} \mathrm{C}$, the thermal conductivity of the waste diatomite sintered porous ceramics was $0.277,0.279,0.280$, and $0.282 \mathrm{~W} / \mathrm{mK}$. Additionally, the thermal conductivity of porous ceramic samples increased with the heating temperature. When the amount of sodium silicate sand was increased from $5 \%$ to $20 \%$, the thermal conductivity of the sintered porous ceramics was $0.331-0.43,0.349-0.489,0.378-0.525$, and $0.399-0.561 \mathrm{~W} / \mathrm{mK}$. Moreover, the thermal conductivity of the porous ceramic samples increased with the sodium silicate sand content. This increase was attributed to the porous structure of sintered porous ceramic samples containing sodium silicate sand, resulting in a denser structure. In addition, the thermal conductivity decreased because of the decreasing density of the sintered porous ceramic samples, which subsequently increased the void content. The samples revealed a correlation between the density and thermal conductivity for sintered porous ceramic samples, in which the thermal conductivity increased with the density. In this study, the porous ceramic samples had a thermal conductivity of approximately $0.278-0.561 \mathrm{~W} / \mathrm{mK}$, which was lower than that for the concrete $(1.458 \mathrm{~W} / \mathrm{mK})$. The porous ceramic samples exhibited properties of low thermal conductivity, which may be attributed to the larger number of pores compared to those in the concrete.

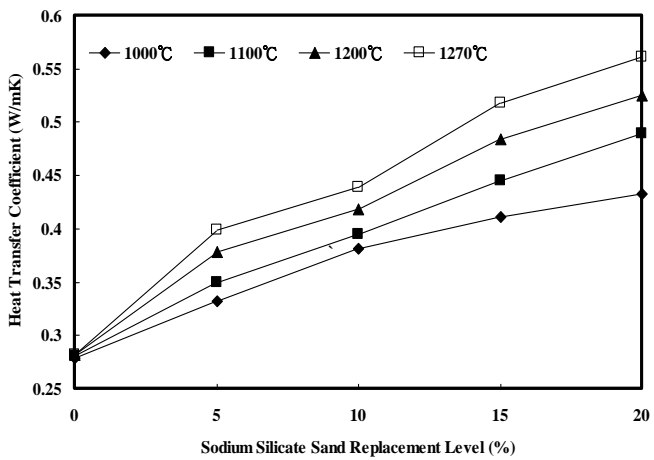

Fig. 1. Thermal conductivity of porous ceramics.

\section{Water-Retention Properties of Porous Ceramic Samples}

The water-release parameter $\left(\mathrm{t}_{1 / 2}\right)$ was defined by the time required for half of the amount of water to be released from the samples. Fig. 2 shows the $t_{1 / 2}$ values as a function of the sodium silicate sand content of the samples. The $t_{1 / 2}$ values are low, with $50 \%$ of the Wa retained for $48 \mathrm{~h}$ in the porous ceramic samples containing sodium silicate sand samples at a relative humidity of $55 \%$ at $20{ }^{\circ} \mathrm{C}$; this value is lower than that in pure diatomite porous ceramic samples when the heating temperature reached $1000{ }^{\circ} \mathrm{C}$. Increasing the heating temperature from $1000{ }^{\circ} \mathrm{C}$ to $1200{ }^{\circ} \mathrm{C}$ decreased the water-retention properties of the resulting porous ceramic samples containing sodium silicate sand samples. When the heating temperature reached $1000{ }^{\circ} \mathrm{C}$, the porous ceramic samples containing $20 \%$ sodium silicate sand had $\mathrm{t}_{1 / 2}$ values of approximately $14 \mathrm{~h}$; these values were larger than those for the porous ceramic samples containing $5 \%$ of the sodium silicate sand $(7 \mathrm{~h})$. Because the $\mathrm{t}_{1 / 2}$ value of the foamed glass sample was approximately $4 \mathrm{~h}$, the porous ceramic samples containing the sodium silicate sand exhibited excellent slow water-releasing properties, which may be attributed to the smaller pores, compared to those in the foamed glass. The large amounts of sodium silicate sand in the porous ceramic samples also facilitated a slow water release, which yielded acceptable water-retention properties. These properties make the porous ceramic samples containing sodium silicate sand samples promising for use as water-retaining materials to combat "heat island" effects.
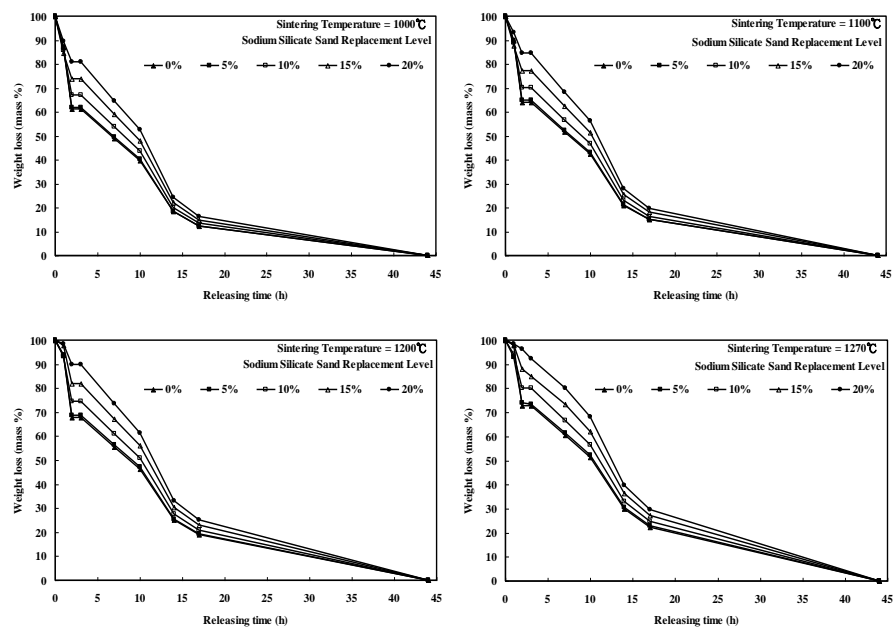

Fig. 2. Water-retention properties of sintered porous ceramics samples at various temperatures. 


\section{E. Distribution of Sizes and Total Volume of Pores in Ceramics}

Fig. 3 plots mercury intrusion data obtained upon heating to $1100^{\circ} \mathrm{C}$. Fig. 3 (a) includes one strong peak with a range of pore sizes of approximately $1.5-2 \mu \mathrm{m}$, and a smaller peak at $0.5-1 \mu \mathrm{m}$. The pores with sizes of $1.5-2.5 \mu \mathrm{m}$ are linked to the voids among the powder particles, while those with sizes of around $0.3-1.5 \mu \mathrm{m}$ are the pores that are inherent to diatomite porous ceramics samples (Fig. 4 (a)). The main peak shifts to a smaller pore size as the heating temperature increases. Figure 4 plots the mercury intrusion data obtained upon heating to $1200^{\circ} \mathrm{C}$. Fig. 4 (a) includes one strong peak at pore sizes of around 1.5-2.5 $\mu \mathrm{m}$, and a smaller peak at 0.3-1 $\mu \mathrm{m}$. Fig. 5 plots mercury intrusion data obtained upon heating to $1270^{\circ} \mathrm{C}$. Fig. 5 (a) includes a strong peak at pore sizes of approximately 1-3 $\mu \mathrm{m}$, and a smaller peak around 0.8-1 $\mu \mathrm{m}$. Accordingly, the sizes of the interparticle pores decrease as the peak temperature increases, and the interparticle voids become partially filled with the melt and/or collapse.

Figs. 3-5 (b) display the evolution of the porosity of sintered bodies that contained sodium silicate sand. They plot, the cumulative volume of pores against pore size. The sintered samples that were prepared from diatomite that contained more sodium silicate sand had smaller pores. The figures demonstrate that the porous diatomite ceramics samples had a greater volume of pores. However, for both types of sample, the dependence of total volume on sodium silicate sand content is strongest between 15 and $20 \mathrm{wt}$. \% (Figs. 3-5(b)). Figs. 3-5 (b) present the evolution of relevant morphological parameters, such as total $\mathrm{Hg}$ intrusion volume (porosity) and average size of interconnecting pores such as the pore necks among the particles of the sodium silicate sand in the samples with sodium silicate sand contents from 10 to $20 \mathrm{wt}$. \%. However, as the concentration of sodium silicate sand increases, the sodium silicate sand begins to interact with particle and an open structure that interconnects the fine pores is slowly formed. As expected, porosity and average pore size values depend directly on the sodium silicate sand content. Increasing the amount of sodium silicate sand particles tends to reduce the average distance between diatomite particles in samples that contain sodium silicate sand, and make the diffusion mechanism during sintering more effective.
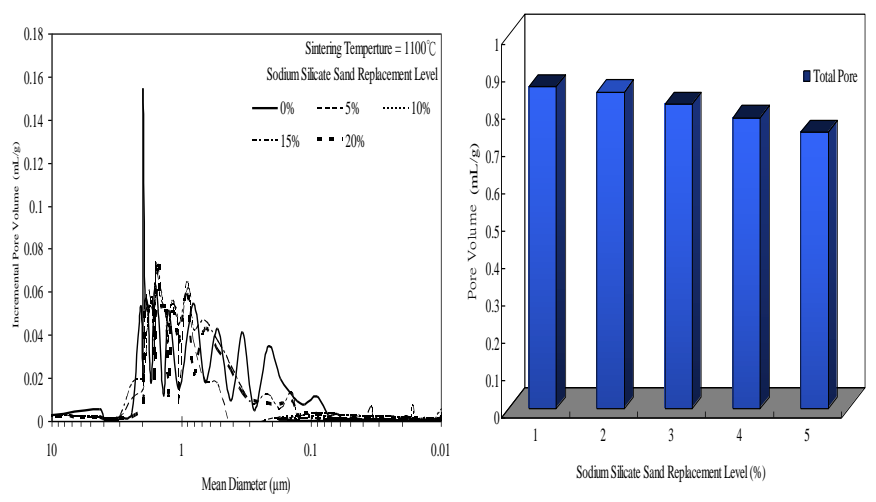

Fig. 3. Distribution of pores in ceramics of porous ceramics sintered at $1100^{\circ} \mathrm{C}$ (a) Distribution of sizes, (b) total volume of pores.
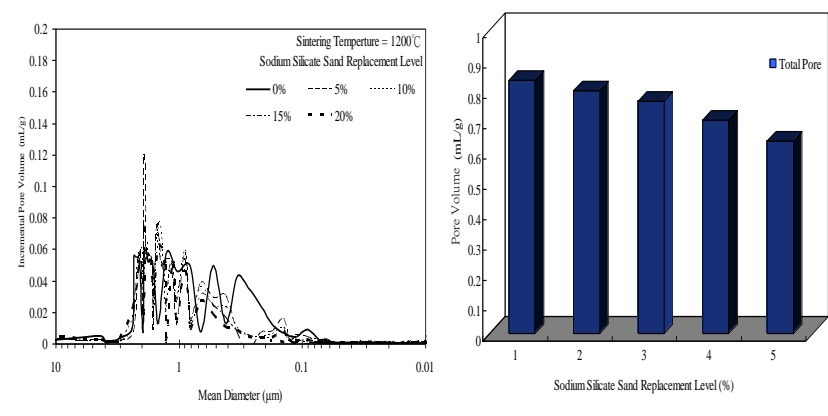

Fig. 4. Distribution of pores in ceramics of porous ceramics sintered at $1200^{\circ} \mathrm{C}$ (a) Distribution of sizes, (b) total volume of pores.
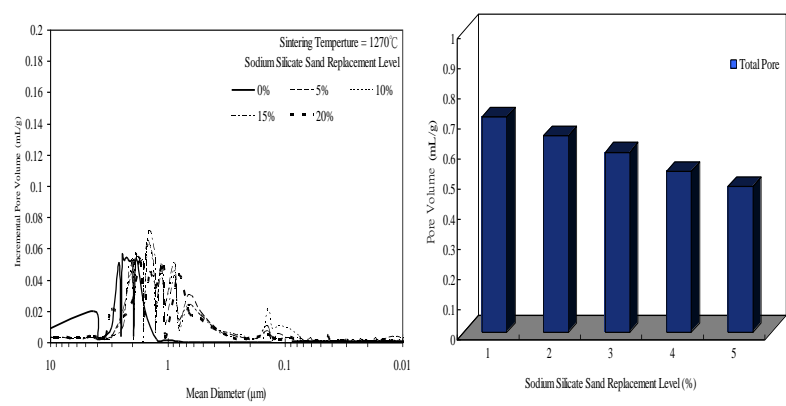

Fig. 5. Distribution of pores in ceramics of porous ceramics sintered at $1270^{\circ} \mathrm{C}$ (a) Distribution of sizes,(b) total volume of pores.

\section{F. FTIR Spectra of Porous Ceramics}

Fourier transform infrared spectroscopy (FTIR) is an effective method for determining mineral composition. Vibrational spectroscopy can help identify high-crystalline substances as well as weak-crystalline and amorphous inorganic components and organic substances. Fig. 6 shows the FTIR spectra of porous ceramic samples at $1270{ }^{\circ} \mathrm{C}$. All specimens were dried at $105{ }^{\circ} \mathrm{C}$ for a few hours prior to spectroscopic measurement to eliminate spurious water bands caused by moisture, which may influence fundamental $\mathrm{OH}$-stretching bands. The porous ceramic samples that did not contain the sodium silicate sand yielded a signal at 622 $\mathrm{cm}^{-1}$, which is characteristic of $\mathrm{Si}-\mathrm{O}-(\mathrm{Si}, \mathrm{Al})$ vibration, suggesting that they contained an alumino-silicate phase. The signal at $1105 \mathrm{~cm}^{-1}$ indicated the formation of $\mathrm{Si}-\mathrm{O}-\mathrm{Si}$ bonds. Porous ceramic samples that contained sodium silicate sand yielded a signal at $472-486 \mathrm{~cm}^{-1}$, which is characteristic of Si-O-(Si, Al) vibration, suggesting that the samples contained alumino-silicate. This signal resulted from the formed $\mathrm{Si}-\mathrm{O}-\mathrm{Si}$ bonds (in the range 1066-1103 $\mathrm{cm}^{-1}$ ), which had strong bands associated with $\mathrm{SiO}_{4}$ tetrahedra in the other phases in the samples.

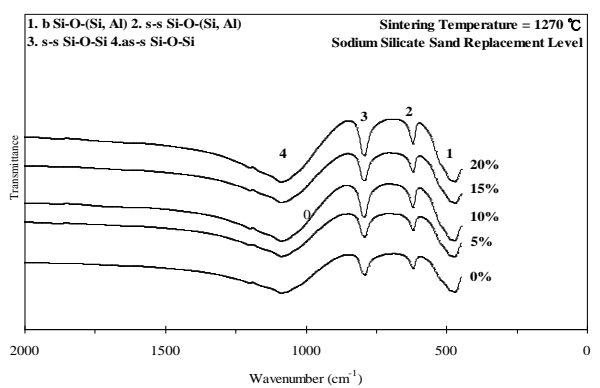

Fig. 6. FTIR spectral patterns of porous ceramics samples at $1270^{\circ} \mathrm{C}$. 


\section{G. Scanning Electron Microscopic Microphotographs of} Porous Ceramics

Fig. 7 shows the SEM microphotographs of porous ceramic samples sintered at $1270{ }^{\circ} \mathrm{C}$. Fig. 7(a) shows that a small fraction of the diatomite powder began to melt, the liquid phase accumulated in regions with a negative curvature, and the contact points between pairs of particles formed necks. The initially isolated diatomite particles were converted into an integral body, which contained numerous closed pores. A microstructural change was observed during sintering below $1270{ }^{\circ} \mathrm{C}$. Cylindrical diatomite particles were identified easily, and a number of micropores were distributed. Scanning electron microscopic measurements revealed the sodium silicate sand in various proportions in the microstructures of porous ceramics (Figs. 7(b)-7(e)). The sodium silicate sand bonded the diatomite powder into relatively strong monoliths. However, a melt phase covered the diatomite particles and filled the diatomite pores when the sintering temperature was increased to $1270{ }^{\circ} \mathrm{C}$. Impurities in diatomite, such as $\mathrm{MgO}$, favor the formation of low-temperature eutectics and the subsequent formation of a melt phase in the silica-rich grains [6]. The internal pore volume of diatomite that contained $20 \%$ of the sodium silicate sand was not reduced substantially after heating to $1270{ }^{\circ} \mathrm{C}$ (Fig. 7 (e)). Slight fusion occurred at the particle contact points at $1270{ }^{\circ} \mathrm{C}$. The powder partially melted, and both the antiparticle pores and the internal structure collapsed.

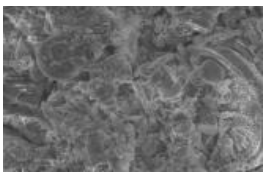

(a) $0 \%$

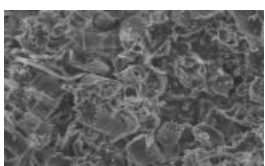

(d) $15 \%$

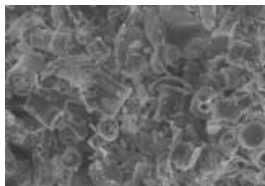

(b) $5 \%$

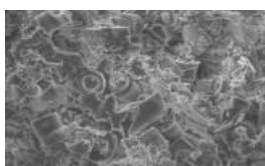

(e) $20 \%$

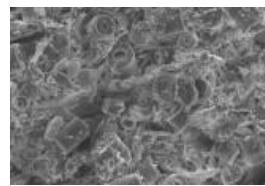

(c) $10 \%$
Fig. 7. SEM microphotographs of porous ceramics samples.

\section{CONCLUSIONS}

This study examined potential waste diatomite and sodium silicate sand reuse in the preparation of water absorption and retention of porous ceramics. The experimental results indicate that increasing the heating temperature from $1000{ }^{\circ} \mathrm{C}$ to $1270{ }^{\circ} \mathrm{C}$ can increase the compressive strength of the porous ceramics.

The porous ceramics fabricated from waste material exhibited enhanced water absorption and retention capabilities. Moreover, the results of this study also indicated that water absorption and retention are dependent on the pore structures. Heating temperature is the crucial parameter in the controlled densification of porous ceramics and in forming monoliths with a well-defined porosity. The signal at 1105 $\mathrm{cm}^{-1}$ indicated the formation of $\mathrm{Si}-\mathrm{O}-\mathrm{Si}$ bonds. Porous ceramic samples that contained sodium silicate sand yielded a signal at $472-486 \mathrm{~cm}^{-1}$, which is characteristic of Si-O-( $\mathrm{Si}$,
$\mathrm{Al}$ ) vibration, suggesting that the samples contained alumino-silicate. The porous ceramic samples containing the sodium silicate sand exhibited low thermal conductivity properties, which may be attributed to the larger number of pores than those in the concrete.

Additionally, water release $\left(t_{1 / 2}\right.$ value) by the porous ceramic samples was decelerated using porous ceramic samples containing the sodium silicate sand because of the synergy effect of high water absorption by the sodium silicate sand. Slight fusion occurred at the particle contact points at $1270^{\circ} \mathrm{C}$. The powder partially melted, and both the antiparticle pores and the internal structure collapsed. The $t_{1 / 2}$ values of the porous ceramic samples were higher than those in the foamed glass material.

\section{ACKNOWLEDGMENT}

The authors would like to thank the National Science Council of the Republic of China, Taiwan, for financially supporting this research under Contract No. NSC 101-2221-E-197- 010- MY3.

\section{REFERENCES}

[1] K. Okada, A. Ooyama, T. Isobe, Y. Kameshima, A. Nakajima, and K J. D. MacKenzie, "Water retention properties of porous geopolymers for use in cooling applications," J. Euro. Ceram. Soc., vol. 29, pp. 1917-1923, 2009.

[2] J. Sheng, "Vitrification of borate waste from nuclear power plant using coal fly ash. (I) Glass formulation development," Fuel, vol. 80, pp. 1365-1369, 2001.

[3] P. Dibandjo, L. Bois, C. Estournes, B. Durand, and P. Miele, "Silica, carbon and boron nitride monoliths with hierarchical porosity prepared by spark plasma sintering process," Micropor. Mesopor. Mat., vol. 111, no. $1-3$, pp. 643-648.

[4] A. Eugene, "Theory of sintering: from discrete to continuum," Mater Sci. Eng., R, vol. 32, pp. 41-100, 1997.

[5] T. Kato, K. Ohashi, M. Fuji, and M. Takahashi, "Water absorption and retention of porous ceramics fabricated by waste resources," J. Ceram. Soc. Japan., vol. 116, no. 2, pp. 212-215, 2008.

[6] ASTM C 1113-90, Test Method for Thermal Conductivity of Refractories by Hot Wire, Platinum Resistance Thermometer Technique.

[7] F. Akhtar, Y. Rehman, and L. Bergström, "A study of the sintering of diatomaceous earth to produce porous ceramic monoliths with bimodal porosity and high strength," Powder Technol., vol. 201, no. 3, pp. 253-257, 2010.

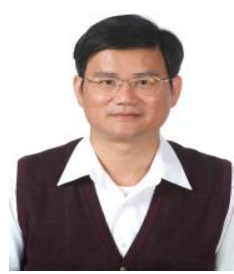

Kae-Long Lin is a professor in Department of Environmental Engineering National Ilan University, Taiwan, 26047, Republic of China. To pursue a research career in Pozzolanic reaction/ Eco-cement/ Waste Treatment/Management/ recycle/ E-waste recycle.

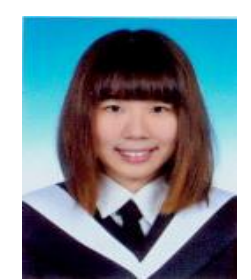

Ju-Ying Lan received the B.S. degree in environmental engineering from National I-Lan University, I-Lan, Taiwan, in 2007. She is currently a master in Deapertment of Environmental Engineering National Ilan University, Taiwan.Department of Environmental Engineering, National Ilan University, 1, Sec. 1, Shen-Lung Road, I-Lan 260, TaiwanROC. 